\title{
Damping Properties of Lead Metaniobate
}

\author{
Taeyong Lee and Roderic S. Lakes
}

\begin{abstract}
Mechanical damping, tan $\delta$, of lead metaniobate was determined experimentally over a wide range of frequency. Damping at audio and sub-audio frequency was lower than at ultrasonic frequency. The experiments were conducted in torsion and bending using an instrument capable of determining viscoelastic properties over more than 10 decades of time and frequency. Mechanical damping was higher in bending than torsion at all frequencies. Damping observed in this study at the highest frequencies approach the high value 0.09 previously observed at ultrasonic frequency.
\end{abstract}

\section{INTRODUCTION}

$\mathrm{V}$ ISCOELASTICII'Y in transient expcriments is manifested as creep (increase of strain under constant stress) or relaxation (decrease of stress under constant strain). Viscoelasticity in dynamic tests with sinusoidal loading is manifested as a phase angle $\delta$ botween stress and strain; tan $\delta$ is reforred to as mechanical damping and is approximately equal to the inverse of the mechanical quality factor Q. Polymers [1] often exhibit large viscoelastic effectis (the loss tangent, $\tan \delta$ from 0.1 to 1 or more) at ambicnt temperature. In structural metals [2], [3], such as steel, brass, and aluminum, viscoclastic cffects are usually small ( $\tan \delta$ of $10^{-3}$ or less); some alloys cxhibit a small tan $\delta<10^{-5}$. All matcrials cxhibit some viscoelastic response. High mechanical damping in metals is of interest in the context of damping of ship propellers [4] or in applications such as solders, involving temperatures that are a large fraction of the melting point [5]. Piezoelectric materials are also of interest in the damping of structural vibrations. A resistive circuit element can be attachod to a piezoclectric inclusion in the structure or material to achicve substantial damping [6], [7], [8]. Lumped circuit elements are cumbersome; therefore, a distributed damping system would be of practical value. Damping of lead metaniobatc is of interest because it does not depond on the presence of an external circuit; it is intrinsic to the material.

Lead metaniobate is a piezoelectric and ferroelectric material originally notable [9], [10] for its high Curie temperature. In ceramic form, it exhibits a Young's modulus $\mathrm{E}$

Manuscript roceived July 8, 1999; accopted January 21, 2000. 'This work was supported by NSF grant no. CMS-9896284.

T. Lee is with the Department of Biomedical Engineering, University of Wisconsin--Madison, Madison, WI 53706-1687.

R. S. Lakes is with the Departments of Engineering Physics and Biomedical Engineering, the Engincoring Mechanics Prograrm, and the Materials Science Program and Rheology Center, University of Wisconsin-Madison, Madison, WI 53706-1687 (e-mail lakes@engr.wisc.edu).
$=46 \mathrm{GPa}$ and viscoelastic damping $\tan \delta=0.09$ in the longitudinal direction [11]. The damping is large for a ceramic and is large for a material of that stiffness. By contrast, shear moduli in other piczoelectric ceramics range from 21 to $45 \mathrm{GPa}$ and $\tan \delta$ from $3 \times 10^{-3}$ to 0.02 for lead titanate zirconates. The high damping of lead metaniobate is useful in generating and receiving pulsed waveforms via ultrasonic transduccrs.

Damping of lead metaniobate has been reported only at a resonant ultrasonic froquency. The present study was conducted to explore its damping over a range of frequency.

\section{Ma'terials nND Metiods}

Specimens of lead metaniobate wore prepared from commercially available transducer disks (Valpey-Fisher Corporation, Hopkinton, MA). These were poled by the manufacturer for use in transducers. A low specd diamond wafering saw was used to cut prismatic specimens 1 to $2.4 \mathrm{~mm}$ across and 10 to $22 \mathrm{~mm}$ long. Two samples were prepared from a $2.4-\mathrm{cm}(1-\mathrm{in})$ diameter disk in the $\mathrm{x}$-direction (transverse to the disk normal) with dimensions $1.5 \times 1.5 \times 10.5 \mathrm{~mm}$ and in the z-dircction (longitudinal, parallel to the disk normal) with dimensions $2.4 \times 2.2 \times 21.3 \mathrm{~mm}$. Only a transverse sample could be obtained from the 1.2-cm (0.5-in) diameter disk because of its small thickness of $3.4 \mathrm{~mm}$. Careful handling of the sample was required for test preparation because the coramic is brittle.

Viscoclastic measurcments were performed in torsion and bending at $23 \pm 1^{\circ} \mathrm{C}$ using apparatus of Chen and Lakes [12] as modified by subscquent workers [13], [14], [1.5]. This device (Fig. 1) permits measurements over as much as 11 decades of time and frequency under isothermal conditions [16]. Such capability is particularly useful in the study of matcrials that are not thermorheologically simple. The wide frequency range is obtained by eliminating resonances from the devices used for loading and for displacement measurement, by minimizing the inertia attached to the specimen, and by use of a geometry, giving rise to a simple specimen resonance structure amenable to simple analysis. Torque was produced by the electromagnetic action of a Helmholtz coil upon a high intensity neodymium iron boron magnet at the specimen-free end. The elcctrical input was sinusoidal for dynamic studies and step function for crecp studies. Angular displacemont was measured via a split-diode light detector that measured the motion of laser light reflectod from a small mirror upon the magnet. The detector signal was amplified 


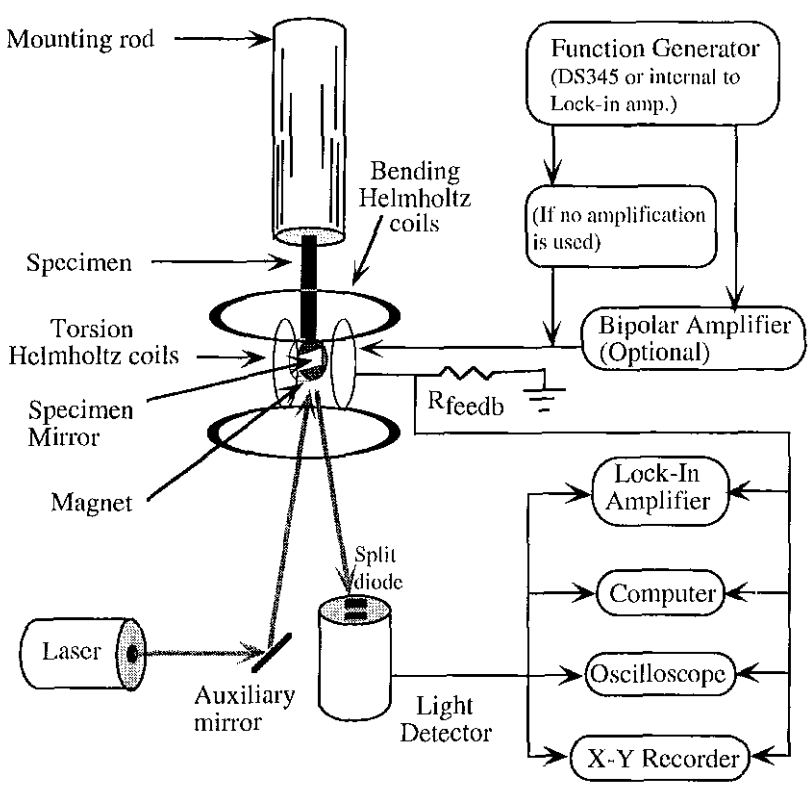

Fig. 1. Schematic diagram of the broadband viscoelastic spectroscopy apparatus.

with a wideband differential amplifier. Tan $\delta$ at resonant, frequencies was inferred from the width of the dynamic compliance curve or from free decay of vibration. In the subresonant domain, $\tan \delta$ was inferrod from the phase angle between torque and angle. Calibrations were performed using the woll-characterized 6061-T6 aluminum alloy $(\mathrm{G}=$ $25.9 \mathrm{GPa} ; \tan \delta \approx 3.6 \times 10^{-6}$ ) [17].

Quasistatic (creep) experiments were conducted by applying a step function current and monitoring both the current and the angular displacemont signal as a function of time. Near resonances, signals were moasured using a digitizing oscilloscope. At low frequency, the phase angle betwecn torque and angular displacement was determined from the width of elliptic Lissajous figures. Creep and low frequency data were acquired via a digital data acquisition system containing a Macintosh Ilci computer and LabVIEW ${ }^{\circledR}$ (Apple Computer, Cupertino, CA. interface hardware and software. At frequencies above $0.01 \mathrm{H} z$, phase angle was determined using a lock-in amplifier (SRS 850, Stanford Rescarch, Sunnyvale, CA) with claimed phase resolution 0.001 deg. The frequency range was scgmented into regions less than $1 \mathrm{~Hz}$ and grcater than $1 \mathrm{~Hz}$ because the wide frequency range necessitated different time constant; settings. Load level was intentionally varied in tests of linearity at the higher frequencies. The instrument was isolated from vibration via a system of springs and viscoelastic elastomer. Low froquency noise caused by air currents was climinated by a Plexiglas ${ }^{\circledR}$ cover.

Data reduction was conducted as follows. For frequencies sufficicntly below the first natural frequency, torsional stiffness is given by $\left|G^{*}\right| \approx K \frac{\left|M^{*}\right| L}{\theta}$, and loss is given by $\tan \delta \approx \tan \phi$ in which $\mathrm{K}$ is a geometrical factor for

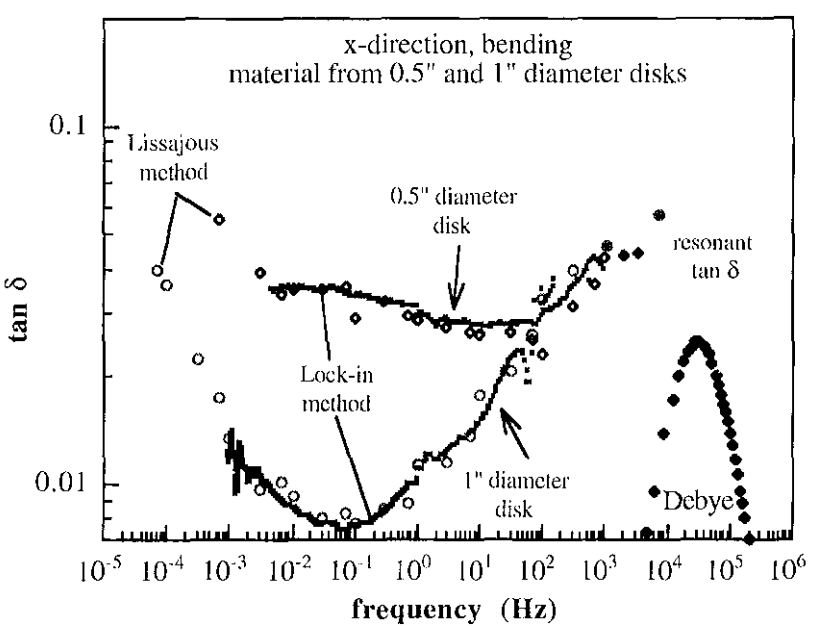

Fig. 2. tan $\delta$ of matorial from 0.5 - and 1-in diametor discs in $\mathrm{x}$ direction, bonding.

torsion of a rectangular section and $\phi$ is the observed phase differcnce. For quasistatic bending, $\left|E^{*}\right| \approx \frac{\left|M M^{*}\right| I}{\frac{1}{12} b h^{3} \theta}$, with $b$ and $h$ as the rectangular cross-section dimensions. In the subresonant domain, the lumped relation tan $\delta=\tan \phi\left(1-\left(\omega / \omega_{0}\right)^{2}\right)$ was used, with $\omega_{0}$ as the fundamental resonance angular frequency. An cxact solution is available [18] but is not nocded unless $\tan \delta>0.2$. At the resonance angular frequencies $\omega_{0}$ in torsion and bending, damping was calculated using the width $\Delta \omega$ at half maximum of the curve of dynamic structural compliance $\theta / M^{*}$ as follows:

$$
\tan \delta \approx \frac{1}{\sqrt{3}} \frac{\Delta \omega}{\omega_{0}}
$$

In most experiments, input voltage (and thus shear stress) was held constant. The maximum surface strain at $1 \mathrm{~Hz}$ was $3.18 \times 10^{-6}$ for torsion and $4.61 \times 10^{-6}$ for bending. To distinguish linear from nonlinear behavior, the shape of the Lissajous figures was examined, and some tests wore repcated al different strain levels.

\section{Resuits AND Discussion}

Results for load motaniobate shown in Fig. 2 to 5 for both bending and torsion disclose $\tan \delta$ in the range from 0.007 to 0.1. Damping results obtained from Lissajous figures are shown as open symbols. Damping results obtained from the lock-in amplifier aro shown as small solid symbols. No deviations from linearity were observed at the small strains used in this study. The instrument's capability for a wide frequency range is attained at the expense of high load capability. At large strains we would expect to observe nonlinear bchavior.

Fig. 2 discloses the damping properties in bending of (transverse) $x$-direction specimens. Tan $\delta$ of material from 0.5 - and 1-in diameter discs showed a relative minimum 


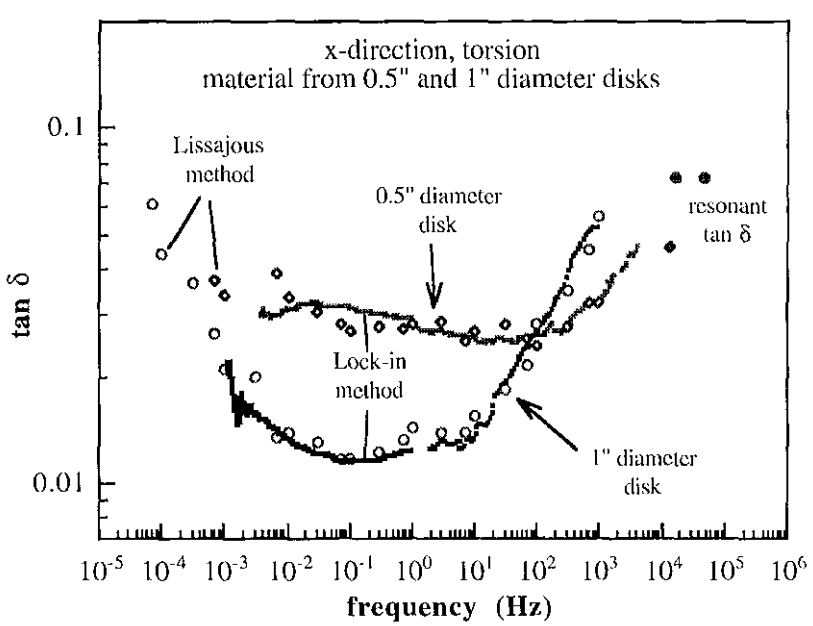

Fig. 3. tan $\delta$ of material from 0.5 - and 1-in diamcter discs in $\mathrm{x}$ direction, torsion.

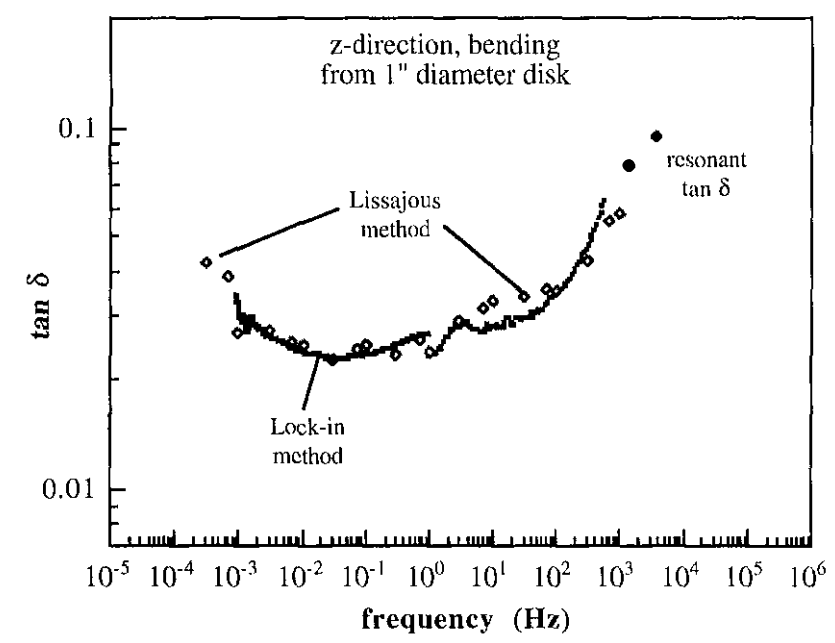

Fig. 4. $\tan \delta$ of material from 1-in diameter dises in z-direction, bending.

at sub-audio to low andio frequency. A similar minimum occurred in torsion for the x-dircction as well, as scen in Fig. 3. The sample from the 0.5-in diameter disc showed similar $\tan \delta$ in both bending and torsion tests, but showed higher $\tan \delta$ at resonances in torsion. Overall damping in torsion was higher than in bending. Fig. 4 and 5 disclose $\tan \delta$ of material from 1-in diameter lead metaniobate in the (longitudinal) $z$-direction. In the bending test, as secn in Fig. 4, higher $\tan \delta$ at resonances was observod than in torsion. Also, mechanical damping was higher in bending than torsion at all frequencies. However, the torsion studies disclosed higher $\tan \delta$ in frequencies above $1.00 \mathrm{~Hz}$ as seen in Fig. 3 and 5 . Tan $\delta$ below $100 \mathrm{~Hz}$ was higher in the bending test. Damping values differed in the $\mathrm{x}$ and $\mathrm{z}$ directions. Anisotropy is expected in a polarized, polycrystalline sample. Morcover, samples from different size transducer disks exhibited different damping, presumably as a

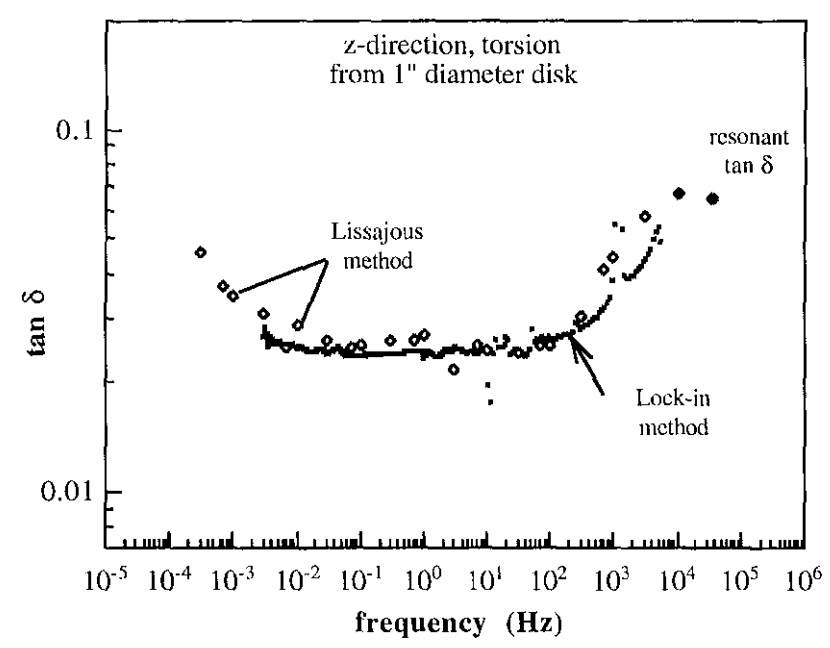

Fig. 5. tan $\delta$ of material from 1-in diameter discs in z-direction, torsion.

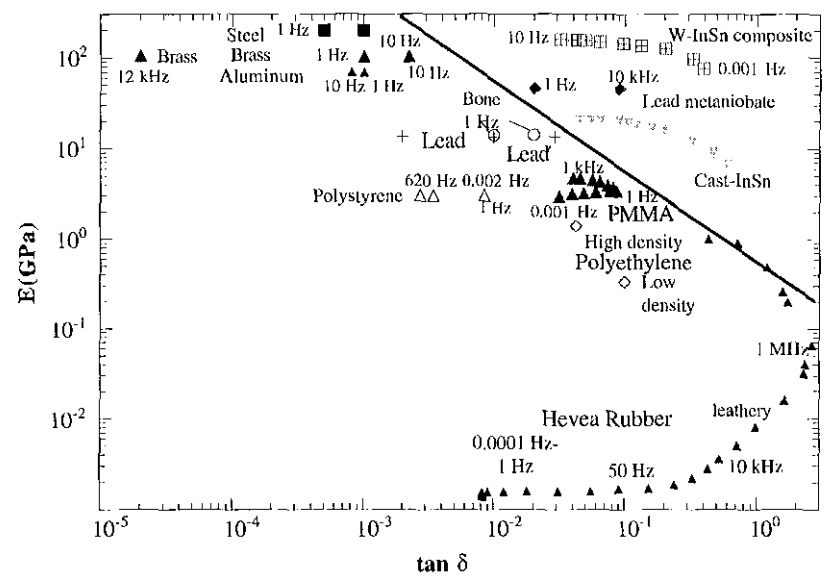

Fig. 6. Stiffhess loss map showing comparison of lead metaniobate properties with those of other materials.

result of differences in the pressing and sintering procoss. Damping observed in this study at the highest frequencies approaches the high value 0.09 previously observed at ultrasonic frequency.

Piezoclectric materials may be of use in the damping of structural vibrations. Damping of lead motaniobate is of interest in that context because it is intrinsic to the material and because the matcrial is relatively stiff. Properties of lcad metaniobate are compared with other materials [19] in the stiffness-loss map in Fig. 6. $\mathrm{E} \tan \delta$ is a figure of merit for vibration absorption. The diagonal line in Fig. 6 presents the largest product ( $\mathrm{E} \tan \delta \approx 0.6 \mathrm{GPa}$ ) of stiffness $\mathrm{E}$ and damping found in common materials, including polymors through the glass-rubber transition and soft metals such as $\mathrm{Pb}$. Stiffness is considered as the absolute value of the complex dynamic Young's modulus $\left|E^{*}\right|$. It is possible to achicve higher $\mathrm{E}$ tan $\delta$ in composites designed to achicve such a figure of morit (for vibration absorption), as 
done by Brodt and Lakes [20], but such a combination is unusual in materials other than designed composites. Lead metaniobate has a reasonably high product $\mathrm{E} \tan \delta$, particularly at the higher acoustic frequencies. It could be used as a constituent in high damping composite matcrials.

As for transduccr applications, the present results inform the designer that load motaniobate has a lower $\tan \delta$ at acoustic frequencies, which may be encountered in bimorphs or other bender clements, than it does at 11ltrasonic frequencies used in determining the 'book value' of tan $\delta$.

As for causal mochanisms, some processes such as dielectric rolaxation caused by point defects in ferroelectrics give rise to a Debye form [21]. The Debyo model for relaxation in the time domain is

$$
E(t)=E_{2}+E_{1} e^{-t / \tau_{r}}
$$

The corresponding Debye peak in $\tan \delta$ in the frequency domain covers about one decade and is as follows. The frequency dependence is shown in Fig. 2 for comparison with the behavior of lead metaniobate.

$$
\tan \delta(\omega)=\frac{\Delta}{\sqrt{1+\Delta}} \frac{\omega \tau_{m}}{1+\omega^{2} \tau_{m}^{2}}
$$

where $\tau_{m}=\tau_{r} \sqrt{1+\Delta}$ is a time constant, $\omega=2 \pi \nu$ is angular frequency, and $\nu$ is frequency. The relaxation strength $\Delta$ is defined as the change in stiffness during relaxation divided by the stiffness at long time. Clearly, the obscrved damping covers a much broader range of frequency than a Debye peak; thereforc, simple mochanisms that give rise to such behavior cannot play a major role. Mcchanical damping in forroolectrics and ferromagnetics can occur as a rcsult of drag becausc of interaction betwecn stress-induced domain wall motion and defocts [22], including dislocations [23] and point defects [24] such as vacancies [25]. Intcraction between domain walls and point defects can also give rise to dielectric loss [26] in multiple relaxation mochanisms that arc operative in ferroelectrics. In temperaturedependent dielectric relaxation, low frequency dispersion is believed to originate from domain wall relaxations rather than heat diffusion [27]. The present study of dependence of $\tan \delta$ on frequency $\nu$ shows the domain wall drag cannot be simply viscous; if it were, $\tan \delta \propto \nu$. Moreover, the damping is not of the hysteresis type; if it were, $\tan \delta$ would be independent of frequency. The attainment of a complete understanding of the causal mechanisms for damping in ferroelectrics is a subject of future study.

\section{CONCLUSIONS}

Mcchanical damping of lead metaniobate was observed to be lower in the audio frequency range than at ultrasonic frequency. The present results at the lower ultrasonic frequoncies are consistent with the accepted values of damping for lcad metaniobate.

\section{REFERHNCWS}

[1] J. D. Ferry, Viscoelastic Propertics of Polymers. 2nd ed. New York: John Wiley, 1979

[2] C. Zoner, Flasticity and Anelasticity of Metals. Chicago, IL: University of Chicago Press, 1948.

[3] A. S. Nowick and B. S. Berry, Anelastic Relaxation in Crystalline Solids. New York: Acarlemic I'ross, 1972, pp. 435- 462.

[4] I. G. Ritchic, K. W. Sprungmann, and M. Sahoo, "Internal friction in Sonoston- $-\Lambda$ high damping $\mathrm{Mn} / \mathrm{Cu}$-based alloy for marine propeller applications," J. Phys, vol. 46, pp. C10-409-C10412,1985 .

[5] T. S. Kô, "Internal friction of motals at very high temperatures," J. Appl. Phys., vol. 21, pp. 414.419, 1950.

[6] R. L. Forward, "Flectronic damping of vibrations in optical structures," J. Appl. Opt., vol. 18, pp. 690-697, 1979.

[7] R. L. Forward and C. J. Swigert, "Electronic damping of orthogonal bending modes in a cylindrical mast-Theory," J. Spacecraft Rockets, vol. 18, pp. 5-10, 1981.

[8] N. W. Hagood and $\Lambda$. von Flotow, "Damping of structural vibrations with piczoclectric materials and passive electrical networks," J. Sourd Vibration, vol. 146, pp. 243-268, 1991.

[9] G. Goodman, "Forroclectric properties of lead metaniobate," J. Amer. Ceram. Soc, vol. 36, pp. 368 372, 1953.

[10] - - , "Ceramic composition," U.S. Patcnt 2805165, 1957.

[11] D). A. Berlincourt, D. R. Curran, and H. Jaffe, "Piczoelectric and piezomagnetic matcrials and their function in transducers," in Physical Acoustics. vol. 1A, E. P. Mason, Ed. 1964, pp. 169270.

[12] C. P. Chen and R. S. Lakes, "Apparatus for determining the propertics of materials over ten decados of frequency and time," J. Rheol, vol. 8, pp. $1231.1249,1989$.

[13] M. Brodt, L. S. Cook, and R. S. Lakes, "Apparatus for moasuring viscoelastic properties over ticn clecades: Refinements," Rev. Sci. Instrum., vol. 66, pp. 5292-5297, 1995.

[14] J. Quackenbush, "Improvoments to a mothod of measuring viscoelastic characteristics of solids," M.S. Thesis, University of Iowa, 1995.

[15] E. B. Garner, R. S. Lakes, T. Lee, C. Swan, and R. Brand, "Viscoelastic dissipation in compact bone: Implications for stressinduced fluid flow in bone," J. Biomech. Eng., vol. 122, pp. $166-172,2000$.

[16] R. S. Lakes and J. Quackenbush, "Viscoclastic bohaviour in indium tin alloys over a wide range of frequency and time," Philosoph. Mag. Lett., vol. 74, pp. 227 232, 1996.

[17] W. Duffy, "Acoustic quality factor of aluminum alloys from $50 \mathrm{mK}$ to 300K," J. Appl. Phys., vol. 68, pp. 5601-5609, 1990.

[18] W. G. Gottenberg and R. M. Christensen, " $\Delta$ n experiment for determination of the mechanical property in shear for a linear, isotropic viscoclastic solid," Int. J. Eng. Sci, vol. 2, pp. 45-56, 1964.

[1.9] R. S. Iuakes, Viscoelastic Solids. I3oca Raton, FL: CRC Press, 1998.

[20] M. Brodt and R. S. Lakes, "Compositc materials which exhibit high stiffness and high viscoclastic damping," J. Composite Mater., vol. 29, pp. 1823-1833, 1995.

[21] M. L. Lines and A. M. Glass, Principles and Applications of Ferroelectrics and Related Materials. Oxford, England: Oxford Univorsity Pross, 1997.

[22] D. Wang, Y. Fotinich, and G. P. Curman, "Influence of temperature on the electromechanical and fatigue behavior of piezoelectric ceramics," J. Appl. Phys., vol. 83, no. 10, pp. 5342-5350, 1998.

[23] A. Wolfenden, "Internal friction in nickel near the Curie temperature," Scripta Mctall., vol. 12, pp. 103-109, 1978.

[24] V. S. Postnilov, V. S. Pavlov, S. A. Gridnev, and S. K. Turkov, "Interaction between $90^{\circ}$ domain walls and point defects of the crystal lattice in forroeloctric ceramics," Sov. Phys. Solid State, vol. 10, pp, 1267-1270, 1968.

[25] B. I.. Chong, M. Gabbay, and G. Fantozzi, "Anelastic relaxation associated with the motion of domain walls in barium titanate ceramics," J. Mater. Sci., vol. 31, pp. 4141-4147, 1996.

[26] J. O. Gentner, P. Gerthson, N. A. Schmidt, and R. E. Send, "Dielectric losses in ferroclectric coramics produced by domain wall motion," J. Appl. Phys., vol. 49, pp. 4485-4489, 1978.

[27] B. G. Kim and J. J. Kim, "Origin of low-frequency dielectric dispersion in KH2PO4 and RbII2PO4 ferroelectric crystals," Phys. 
Rev. B-Condensed Matter, vol. 59, no. 21, pp. 13509-13512, 1999 .

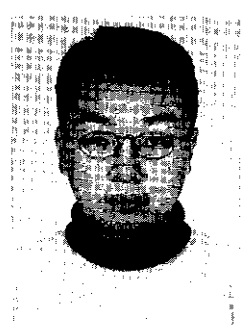

Taeyong Lee received his B.S. degree in biomedical engineering from Inje University, Korca in 1993 and completed his M.S. degree in biomedical engineering from the University of lowa in 1995 . He is currently a candidate for a l'h.D. degrec in the Department of Biomedical Engineering at the University of Wisconsin-Madison. Taeyong Lec's research interests include the study of piezcoelectric and ferroclectric composite materials and thoir applications through the use of micromechanical analysis. He is also a member of the Korean-American Scientists and Fngineers Association.
Roderic Lakes attended Columbia University then carned the B.S. in physics at Rensselacr Polytechnic Institute. He returnod to Renssolaer to carn the l'h.D. in physics in 1975 . Research interests include expcrimental mochanics, including viscoelastic spectroscopy, ultrasonics, and holographic interferometry; characterization of materials such as fibrous composites, cellular solids, biomaterials, dissipativo piezoelectrics, and human tissuc such as bone and ligament; study of structure-property rolationships; and development of materials with novel microstructures and novel properties, e.g., negative Poisson's ratio cellular solids. He is currently Profossor of Engineering Mechanics in the Department of Engineoring Physics at the University of Wisconsin, Madison. Ho is a Fellow of the Amcrican Nssociation for the Advancement of Science (AAAS) and of the American Society of Mechanical Engincors (ASMF). 